\title{
Commonplace and out-of-place diversities in London and Tokyo: migrant-run eateries as intercultural third places
}

\author{
Susanne Wessendorf ${ }^{1 *}$ (D) and James Farrer $^{2}$
}

\author{
* Correspondence: ad5284@ \\ coventry.ac.uk \\ ${ }^{1}$ Centre for Trust, Peace and Social \\ Relations (CTPSR), Coventry \\ University, Coventry CV1 2TL, UK \\ Full list of author information is \\ available at the end of the article
}

\begin{abstract}
In global cities such as London and Tokyo, there are neighbourhoods where ethnic, religious, cultural and other forms of diversity associated with migration are commonplace and others where migrants are regarded as unusual or even out-ofplace. In both types of contexts, migrant-run eateries are spaces in which people of various backgrounds interact. In some contexts, eateries may serve as 'third places' in which regular forms of intercultural conviviality occur, yet in others, interactions are civil but fleeting. This comparative paper is based on findings from two ethnographic neighbourhood studies in West Tokyo and East London. The Tokyo neighbourhood of Nishi-Ogikubo is one of emerging diversity, in which migrant entrepreneurship is rather new and uncommon, whereas East London has seen immigration for decades and migrant-run businesses are so common as to be takenfor-granted. In Tokyo the Japanese norms of 'drinking communication' in small eating and drinking spots inevitably involve migrant proprietors and their customers more deeply in social interactions. In East London, in contrast, intercultural interactions are much more commonplace in public and semi-public spaces, but in the case of migrant-run eateries, they are characterized by somewhat superficial encounters. This paper contributes to scholarship on the role of third places for intercultural relations, highlighting the importance of established cultural norms of interaction in specific third places. By comparing two vastly different contexts regarding the extent of immigration-related diversity, it demonstrates how encounters between residents of different backgrounds are deeply embedded in cultural norms of interaction in these places, and how migrant entrepreneurs in each context adapt to these established norms.
\end{abstract}

Keywords: Intercultural relations, Third places, Tokyo, London, Ethnic businesses, Contact zones

\section{Migrant-run eateries as 'intercultural third places'}

In global cities such as London and Tokyo, there are neighbourhoods where ethnic, religious cultural and other forms of diversity associated with migration are commonplace (Wessendorf, 2014), and others where migrants are regarded as unusual. In both types of urban contexts, eateries are an expression of the 'migrant's dream' of owning

(C) The Author(s). 2021, corrected publication 2021. Open Access This article is licensed under a Creative Commons Attribution 4.0 International License, which permits use, sharing, adaptation, distribution and reproduction in any medium or format, as long as you give appropriate credit to the original author(s) and the source, provide a link to the Creative Commons licence, and indicate if changes were made. The images or other third party material in this article are included in the article's Creative Commons licence, unless indicated otherwise in a credit line to the material. If material is not included in the article's Creative Commons licence and your intended use is not permitted by statutory regulation or exceeds the permitted use, you will need to obtain permission directly from the copyright holder. To view a copy of this licence, visit http://creativecommons.org/licenses/by/4.0/. 
their own business. Due to discrimination on the labour market, opening one's own business can also represent the only way of integrating economically into the local society. More broadly, migrant eateries are 'culinary contact zones,' or spaces in which people of various backgrounds taste unfamiliar foods and participate in cultural exchanges that may be productive and convivial, but also may involve inequality, othering, and even conflict (Farrer, 2015; Hirose \& Pih, 2011).

This article examines the role of migrant-run eateries as 'intercultural third places' in two vastly different contexts of inter-ethnic food consumption, namely Nishi-Ogikubo in Tokyo, and Hackney and Newham in East London. As outlined in the introduction to this special issue, the former is a context of emerging diversity where daily interactions between the Japanese majority and migrants are fairly uncommon. In this context, migrant-run eateries represent the first visible sign of the presence of migrants. East London, in contrast, has seen immigration for decades and migrant-run businesses and restaurants are so common as to be taken-for-granted. In this context of 'commonplace diversity' (Wessendorf, 2014) where intercultural interactions are unexceptional in public spaces, interactions are somewhat fleeting in migrant-run eateries. Beyond these public and semi-public spaces, culinary contact zones also emerge across various everyday realms of life such as among neighbours, in community groups, at school fairs, etc. In Nishi-Ogikubo, in contrast, migrant-run restaurants are the most visible 'culinary contact zones' in a neighbourhood in which such contacts are otherwise rare.

Importantly, it is not only the relatively low migrant presence in Nishi-Ogikubo which renders migrant-run eateries into a primary intercultural space, but also the established cultural norms of interaction in these 'third places' (Oldenburg \& Brissett, 1982). The Japanese norms of 'drinking communication' in small Tokyo eating and drinking spots (Molasky, 2014) inevitably involve migrant proprietors and their customers more deeply in social interactions than in East London's restaurants.

The article draws on the notion of 'contact zones' developed by Pratt and defined as 'social spaces where cultures meet, clash and grapple with each other, often in contexts of highly asymmetrical relations of power, such as colonialism, slavery, or their aftermaths' (Pratt, 1991, p. 34). There is a burgeoning literature looking at such contact zones or 'micro publics' (Amin, 2002) in contexts characterized by immigration-related diversity (Amin, 2002; Neal et al., 2018; Sandercock, 2003; Wessendorf, 2014), and there exists an emerging body of literature into migrant-run businesses as sites of intercultural encounter, discussed later in the paper.

This article builds on this scholarship by developing the notion of 'intercultural third places', drawing on Oldenburg and Brissett (1982) definition of a 'third place' as social surrounding separate from the home and the workplace, for example temples, cafés, libraries, or parks. Intercultural third places are sites where people of different ethnic and cultural backgrounds meet and sometimes interact. ${ }^{1}$ While being aware of the many competing concepts of 'culture' within sociology (Griswold, 2012; Sewell, 2005; Williams, 1995), we here refer to 'culture' as a set of behavioural codes and cognitive

\footnotetext{
${ }^{1}$ We here use Oldenburg's concrete notion of 'third place' (as actual physical place where people meet), not to be confused with the idea of 'third space' developed by Bhabha and referring to a contradictory 'space of enunciation' when two or more individuals of different cultures interact, and within which essentialist notions of bounded cultures are questioned (Bhabha, 1994).
} 
schema that are applied contextually and flexibly, and that are always negotiated situationally (Swidler, 1986).

By comparing two vastly different urban neighbourhoods, this article makes a unique contribution to debates on 'contact zones' and 'third spaces' by identifying three crucial factors which impact on the nature of social encounters in such places, and which to date have been neglected: firstly, the role of the demographic context within which such encounters are situated; secondly, the physical set up of such eateries; and thirdly, the role of established cultural norms of interaction in specific third places.

Most, but not all of the migrant-run eateries examined in the projects presented in this paper represent themselves as 'international' or 'ethnic' restaurants, a term which refers to 'restaurants that market the national or regional cuisine of another country' (Turgeon \& Pastinelli, 2002, p. 252). The restaurants we discuss are all independent migrant-run eateries. We do not consider corporate chain restaurants where migrants may be employees, but where interactions between customers and staff tend to be minimal.

We will first provide an overview of how inter-ethnic food consumption has been discussed in the social sciences, linking these discussions with conceptualizations of ethnic businesses as potential sites of social interactions between people of different backgrounds. We will thereby differentiate between discussions around the role of food consumption with those around the role of the sites within which food is exchanged. This will be followed by a short description of the methods and research sites, then a comparison of data from the two ethnographic fieldsites and a concluding discussion.

\section{The role of food in social contacts across ethnic and cultural difference}

With a growing academic interest in food studies, the migrant-owned eatery has been recognized as a central feature of life in diverse modern cities (e.g. Panayi, 2008; Ray, 2016; Warde, 2000; Zelinsky, 1985). At the same time, a greater emphasis on multicultural coexistence has prompted migration researchers to consider the role of food in facilitating social contacts across ethnic and cultural differences (Rhys-Taylor, 2017; Watson, 2009; Wise, 2011). This has become particularly prominent in the context of increased policy attention to 'social cohesion' and 'interculturalism', which emerged in the context of the backlash against multiculturalism across Europe (Grillo, 2018; Vertovec \& Wessendorf 2010; Wood \& Landry, 2007), and which emphasized the need for different 'groups' to mix across ethnic and religious differences (HM Government, 2018). Much of the discourse on 'social cohesion' portrays mixing across ethnic differences as positive, with studies showing how, especially in social spaces of everyday encounter, people tend to form positive social relations across differences (Amin, 2002; Wessendorf, 2014; Wood \& Landry, 2007). Emerging from this work on social cohesion and interculturalism have been a range of studies focusing on 'conviviality', and examining how people in contexts characterised by immigration-related diversity 'live together successfully, how they create a modus co-vivendi and what strategies they create in order to practice it' (Nowicka \& Vertovec, 2014, p. 342; see also Gilroy, 2006, p. 6).

Other scholars, however, have cautioned that even regular encounters in spaces of social mixing do not necessarily reduce prejudice against people of other groups, criticising discourses on conviviality as celebratory (Valentine, 2008). Wise highlights how food has become a central theme in 'mixing interventions' to increase social 
cohesion, and how it is thereby often assumed that "eating the food of the "other" in intercultural situations will have positive outcomes for race and interethnic relations' (Wise, 2011, p. 83). Such ideas build on the much older notion of 'cosmopolitanism', also defined as 'hospitable engagement with people from elsewhere' (Nava, 2007, p 13). Anderson writes of 'cosmopolitan canopies,' such as ethnic food courts in the central city in which people from very different backgrounds interact civilly and even amiably, often over food. Although most such encounters are brief, some cosmopolitan eating spaces, such as lunch counters, foster deeper conversations (Anderson, 2011).

However, social scientific literature on food and diversity has critiqued interethnic food consumption as superficial engagement with the other which does not go beyond celebratory multiculturalism and ignores deep-seated race-based power relations (Cook, 2008; Gunew, 2000; Hooks, 1998), as exemplified in the British consumption of curries in the context of ongoing white racism (Buettner, 2008) or the Orientalist othering implicit in seeking 'authentic' Asian food in North America (Hirose \& Pih, 2011). Historically, the consumption of 'exotic' ethnic foods was regarded as a form of urban slumming, including patronizing 'chop suey' in US Chinatowns in the early twentieth century (Heap, 2008; Light, 1974). More recently, the avid interest in ethnic foods among Western food adventurers can be regarded as form of colonizing appropriation (Heldke, 2015, p. 57). The label 'ethnic restaurant' has been generally applied to lower status and lower priced restaurant cuisines from developing regions associated with working class migrants (Ray, 2016). We see a similar pattern in Japan in which cuisines from developing countries in Asia are labelled 'ethnic' (esunikku) while those from France or Italy are not (Farrer, 2010). Moreover, an interest in ethnic Asian foods in Japan is associated with the postcolonial nostalgia of tourism to Asian neighbours (Iwabuchi, 2002, pp. 173-5).

In modernizing Japan, the development of foreign restaurants was also shaped by an imperial vision in which Japan was a modern westernized nation, with political and economic elites consuming French cuisine, while also an empire in which the cuisine of a colonized China could be appreciated in a domesticated form (Cwiertka, 2006). After the war most Chinese restaurants, and many other 'ethnic' restaurants, were actually run by Japanese and incorporated into an expansive and flexible concept of modern Japanese foodways (Cwiertka, 2006; Solt, 2014). 'Ethnic' food consumption thus may be based on postcolonial mindsets or, in the case of Japan, 'domesticated' and have little to do with actual intercultural contact (Farrer, 2018; Turgeon \& Pastinelli, 2002).

Drawing on long-term ethnographic fieldwork in Sydney, Wise (2011) shows how it is not food consumption as such which creates bridges between people of different backgrounds, but that it is the 'material, ritual and social settings in which food is consumed cross-culturally' which matter. Food can thereby both enable such relations, but it can also solidify and calcify boundaries (Wise, 2011, p. 107). Hence, there are a range of situations or places in which different foods are consumed, exchanged and shared, and these social settings matter regarding the nature of inter-ethnic encounters.

The following section delves into social scientific discussions around ethnic businesses and restaurants as sites of interethnic interaction and food consumption. 


\section{Migrant-run businesses as sites of social interaction}

Chicago school urban sociologists focused on interactions between ethnic and racial groups in the commercial spaces of diversifying twentieth century US cities. Based on fieldwork in the early 1960s, Gerry Suttles described how one Italian restaurant in a Chicago neighbourhood served simultaneously as a community space for ItalianAmerican regulars, as a touristic space for rich white outsiders to consume an 'ethnic' atmosphere, and as a spot for African Americans living nearby to purchase cheap snacks. Ethnic hierarchies were expressed through discriminatory 'host-guest' relationships in which affluent whites from outside the neighbourhood were treated more warmly by the Italian 'hosts' than were black patrons living nearby. Suttles characterizes ethnic businesses according to the degree to which they were restricted to one ethnic group or open to encounters with others. Although mixed spaces existed, Suttles writes that residents generally favoured spaces in which they interacted within their own group (Suttles, 1968, pp. 46-54). Overall, Chicago School researchers reported the existence of strong social barriers to intercultural mixing in the commercial contexts they studied.

In the context of an increasing number of migrant-run eateries in London towards the end of the nineteenth century, Panayi (2008) similarly differentiates between 'foreign restaurants' which cater to their own group, those which staffed primarily European migrants but did not specifically serve foreign foods (for example well-known establishments such as the Ritz), including smaller establishments opened by migrants who did not make an issue of their businesses' foreign credentials, and those who specifically sold foreign foods to British customers.

Japanese cities were closed off from foreign trade and migration until the Meiji Restoration of 1860s. By the early 1920s, however, Western and Chinese restaurants were common in Japanese cities, and were important places for culinary exchange, greatly influencing Japanese eating habits. Though they often employed Chinese (and occasionally Western) cooks, most of these pre-war 'foreign' restaurants were Japanese-owned. Migrant-owned restaurants increased only after the 1970s when the yen was revalued and Japan became a high-income society, attracting greater numbers of migrants. In the 1980s, tens of thousands of Chinese students began entering Japan, and some began to open restaurants (Farrer, 2018). More recently South Asians, especially Nepalis, have begun to open restaurants throughout the country (Kharel, 2016). And with the rise of Tokyo as a global food city in the 2000s, prominent foreign restaurateurs have also opened fine dining restaurants in the city, also hiring migrant chefs (Ceccarini, 2011; Farrer, 2010).

In this article, we will focus on everyday eateries which cater to everybody, not exclusive fine dining restaurants. These could also be conceptualised as 'inter-ethnic businesses', where people of certain ethnic backgrounds cater for customers of other ethnic backgrounds. In these places, traders often adapt their produce and behaviour to their customers, making specific efforts to communicate across cultural and linguistic differences in order to facilitate trade, a phenomenon also conceptualized as 'corner-shop cosmopolitanism' (Wessendorf, 2014, see also Pécoud, 2004). Hüttermann (2018) uses the notion of 'intimate market society' to describe how traders and customers sometimes develop situational intimate relations resulting from regular encounters, cultivating a personal-style sociability whereby the stranger becomes a familiar stranger or 
even a 'situational friend'. In her ethnographic study of a multicultural street in Peckham, South London, Hall (2012) has described how in one café, interactions served to sustain familiarity and test knowledge and understanding of different people.

There exists a broad range of social scientific research on how immigration has led to the transformation of 'national cuisines' and how migrants have changed not only what we eat but also the ways in which eateries are run (Assael, 2013; Ceccarini, 2011; Panayi, 2008; Ray, 2016). Our focus in this article is not on the development of multicultural food cultures and changes in local cuisines, but more specifically on whether and how migrant-run eateries are used as a space of sociability. Typically, commercial eateries can be 'third places' between home and work, such as pubs, bars or cafés, in which people develop familiar if not always intimate ties (Oldenburg and Brissett, 1982). In Tokyo, the izakaya (a tavern serving food and drinks), the snack bar (a small bar serving drinks and snacks) and the café (typically serving non-alcoholic drinks) have all been studied as examples of urban 'third places' and spaces of sociability among strangers who may become regulars (Farrer, 2019, 2021; Hashimoto, 2015; Molasky, 2014; Taniguchi, 2017; White, 2012). ${ }^{2}$ A question few studies seem to address, however, is the degree to which migrant-run places can also serve this function. As Suttles's ethnography of businesses in a single city shows, migrant-run eateries could be sites of ethnic exclusion or inter-ethnic interaction (Suttles, 1968). A comparative analysis allows us to see how these patterns of interaction and avoidance are influenced by differences in the social organizations of migrant-run eateries in super-diverse East London and the emerging diverse Nishi-Ogikubo.

\section{Research sites and methodology}

East London has traditionally been the arrival destination for many of London's migrants because of its proximity to the docks and the availability of jobs and relatively cheap housing (Butler \& Hamnett, 2011). The Boroughs of Newham and Hackney form part of East London's typical immigrant reception areas where newcomers find their feet. Both areas saw considerable migration from the Caribbean, South Asia and Africa since the 1940s, over-layered by ongoing immigration from across the world, especially since the 1980s, for example from Vietnam, Turkey and a range of African countries. More recently, East London has seen newcomers from Eastern and Southern Europe as well as Latin America. These migrants are not only differentiated in terms of countries of origin, but also regarding educational, religious, linguistic and socio-economic backgrounds as well as different legal statuses. Hackney's and Newham's white British population now forms a minority of $36.2 \%$ and $16.5 \%$ respectively (Hackney Council, 2013; London Borough of Newham, 2011). Although the areas are fairly large in terms of their populations (with a total of ca. 600,000), we can find similar types of highstreets in both areas with comparable ethnic businesses such as restaurants, cafés, grocery shops, barbers, money transfer agencies, mobile phone shops, etc. These high streets, many of which are dominated by ethnic minority and migrant proprietors, play an important role for local economies and for providing jobs as well as social spaces for marginalized populations (Hall et al., 2017; Jones et al., 2015; We Made That \& LSE Cities, 2017). Hackney and Newham are amongst the most deprived areas of the UK despite

${ }^{2}$ For similar studies in the UK see Laurier and Philo (2006) and Neal et al. (2018). 
noticeable gentrification in recent years and despite only being a stone's throw away from London's financial district (Hackney Council, 2019; London Borough of Newham, 2016).

East London's diversity contrasts greatly with the emerging diversity of West Tokyo. The ethnographic fieldwork in this study was conducted in NishiOgikubo, a neighbourhood in Suginami Ward, the western most of the 23 urban wards of Tokyo. The foreign population of Suginami as of January 1, 2019 was only 17,722 , which is $3.1 \%$ of the ward's total population of 569,132 (Suginami City, 2019). Unlike Shinjuku and a few other areas of Tokyo, Suginami has no dense concentrations of migrant residents or migrant businesses in one neighbourhood. An area that urbanized only in the early twentieth century with the advent of commuter railways centred on Shinjuku Station, Suginami is regarded as a transition zone between urban and suburban Tokyo, housing many affluent and middle-class salaried employees, small business people, officials, and tradespeople. Although Suginami had large factories in the earlier part of the twentieth century, manufacturing moved further out of the city by the 1980 s, the period in which inbound labour migration into Japan began to increase, so there are no concentrations of recent migrant factory workers in Suginami. Still, as in most of urban Tokyo, Suginami provides housing at all price levels. The international migrants who live in Suginami are diverse in ethnicity and profession and dispersed throughout the district, including many of the restaurant and business owners discussed in this article.

Ethnographic fieldwork in London was undertaken as part of two research projects. The project in Hackney entailed 18 months of ethnographic fieldwork, and the one in Newham 15 months. In both areas, fieldwork included interviews and participant observation in local community groups, parents' groups, andpublic spaces such as shops, restaurants, cafés, parks and markets. This paper draws on participant observation in restaurants and cafés, including numerous informal conversations with staff working in such businesses. While the project did not specifically focus on food exchange, food played a crucial role in all community contexts, ranging from sharing food at school fairs, public community events or between neighbours.

Ethnographic research in Tokyo was undertaken as part of a research project on small-scale food-and-beverage entrepreneurs in Nishi-Ogikubo, a neighbourhood known for independently owned businesses, including second-hand shops, bars and restaurants. The project has continued for 5 years and involves ethnographic fieldwork as well as an interview project in which the stories of the owners are shared back with the community on a bilingual webpage (Farrer webpage). (The website has profiled 13 migrant-run eateries, and details of their migrant trajectories can be found there.) Fieldwork has also involved participant observation in shops, restaurants, community events, festivals and block parties. There have been interviews with community leaders such as activists, councillors, realtors, and local historians and scholars. Food service businesses have been the focus of the research project from the beginning, though migration and migrants are only part of project's scope which also includes Japanese-owned and managed businesses. Projects in both countries received ethical approval from the respective Universities (University of Birmingham and Sophia University). 


\section{East London: commonplace migrant-run eateries and the continuing importance of informal food exchange}

Writing about London, Vaughan (2015, p. 45) states that 'the growth of eating out as a leisure practice alongside a dramatic increase in access to formerly 'exotic' foodstuffs means that the cultural consumption of minority food stuffs has become commonplace' (see also Assael, 2013). This also holds true for Hackney and its neighbouring borough Newham, where migrant-run eateries are almost more common than English cafés and restaurants. For example, along a $1.5 \mathrm{~km}$ stretch of Hackney's main high street, we can find 19 migrant-run eateries (excluding larger chain restaurants such as MacDonald's or Nando's, many of which are staffed by migrants). These eateries attract a range of customers. Some mainly attract people of the same background and thus provide communal spaces for co-ethnics. This is exemplified by kosher Pizza take-aways aimed at the Orthodox Jewish community, or little Ghanaian eateries which attract a number of Ghanaian regulars. Similarly, in Newham, we can find a Brazilian café which functions as important place for recently arrived Portuguese-speaking migrants to exchange information about, for example, finding housing or jobs. While customers of other backgrounds rarely enter such spaces, there are exceptions. For example, there is a Bangladeshi café in Newham which offers proper Italian espresso coffee. It is run by people of Bangladeshi background who lived in Italy for many years before moving to London. They cater to an Italian Bangladeshi community in East London which dominates the café. However, they also attract a minority of other customers because of the excellent coffee they serve, and because their café is not advertised as specifically Bangladeshi. Sociability between non-Bangladeshi customers and the proprietors is, however, limited because the two women who run the place speak very little English.

The majority of eateries in East London, however, attract customers of many different backgrounds. In the context of London, where access to foods from around the world at markets, cafés, restaurants and even mainstream supermarkets has become commonplace, ethnic eateries do not specifically function as sites of intercultural connections. Rather, they are part of the broader picture of East London's commonplace diversity (Wessendorf, 2014). For example, during an ordinary weekday evening at a longestablished Turkish restaurant, none of the customers spoke English, but a different language was spoken at each table. Interactions with the Turkish waiters were minimal, as, due to the popularity of the place, there simply was no time for anything more than a brief conversation between waiters and customers.

While the staff working at this Turkish restaurant are all Turkish, this is not the case for all migrant-run eateries. Although most of these eateries serve food originating in the owners' country of origin (e.g. Turkish, Vietnamese, Cuban, Mexican, etc.), the staff working in these sites do not necessarily originate in these places. For example, a Japanese restaurant in the area employs waitresses originating from mainland Europe, and the chefs are of South Asian background. Many of the Turkish eateries employ Eastern European migrants. In Newham, a 'typical' English café is owned by a Turkish man who employs a Lithuanian waitress. There is also an Indian street food joint in Newham, part of a larger chain, which is mainly frequented by young South Asians, both British and foreign born. It is staffed by waiters of both South Asian and Eastern European origin. These eateries, thus, represent the more general demographic picture of the area, characterized by the over-layering of 'old' and 'new' migration (Vertovec, 
2015) where long-established migrants and ethnic minorities provide jobs for newcomers of various backgrounds.

Migrant-run eateries in this context are among many spaces where one might meet others of other ethnic and cultural backgrounds, but not necessarily engage with them beyond fleeting contacts. This is also due to their material set-up where people sit on individual tables, sometimes in groups, and thus build 'private realm bubbles' (Lofland, 1998). Interethnic encounters rarely go beyond the civil and transactional. Within these eateries, consuming 'ethnic food' is somewhat unrelated to actual social engagement with those making or serving this food. In relation to Indian curry restaurants in Britain, Narayan similarly observed how long-established residents integrated Indian cuisine within their culture but did not necessarily integrate Indians themselves (Narayan, 1995).

Hence, migrant-run eateries in East London are not the epicentre of intercultural social interactions because they are situated within a context of commonplace diversity where both consuming different foods as well as social interactions with people perceived as different have become normalized. Furthermore, those working in such eateries are often too busy to have time for informal conversations with customers and, additionally, they are not necessarily from the same country of origin as the food they serve. Lastly, because of the physical set-up of these eateries, and in contrast to many of the Tokyo eateries discussed below, customers rarely interact with people on other tables, but create social bubbles. However, food exchange does still function as bridge between those perceived as culturally different. For example, a young black British man of Nigerian background talked about his positive relations with his Indian neighbours. Coincidentally, he had a BBQ in his garden while his Indian neighbours were having one, too. They brought over some food, which he reciprocated by sharing drinks. This exchange of food and drink ended in several of their children playing together and having a nice time, which, for him, represented the positive side of Hackney's diversity.

An elderly woman of Caribbean background reminisced about her neighbourly relations on the social housing estate where she lives, talking about how she used to sit outside with her Indian and Chinese neighbours during the summer, sharing food, and that her Chinese neighbour has continued to bring food around up until today.

A group of mothers of ethnic minority background in a local primary school participated in a cooking class for parents and talked about how it was one of few opportunities to get to know and engage with mothers of other backgrounds, including learning how to cook their food. A Turkish mother at a different primary school mentioned how food was something that connected her with her neighbours, because they asked her for her recipes once she started sharing food with them. It is thus primarily in the context of informal food exchange between acquaintances where food connects people across differences, but less so in the context of migrant-run eateries. Importantly, these exchanges of food take place in the context of regular encounters, which contrasts the fleeting encounters described in the context of migrant-run eateries in East London. Such more regular encounters through food exchange also enable a deeper engagement across cultural differences (Amin, 2002; Wessendorf, 2014; Wise, 2011).

Food, however, does not always bring people together, and inter-ethnic food and drink consumption can also be divisive, as shown by Wise with the example of AngloAustralians who found it difficult to accept Muslims' refusal to consume alcohol (Wise, 
2011). It can also lead to tensions among individuals who have to share limited spaces in regards to housing, as exemplified by research participants who complained about the smell of neighbours' cooking in apartment blocks, or a Malawian research participant who shared a flat with West African women with whom he got along well enough, but whose food culture he did not agree with. Similarly, a recently arrived migrant woman from Azerbaijan who was sharing a house with five other families complained that when the Bangladeshi residents started cooking, it was time to leave the house.

To summarise, consuming 'ethnic food' is well established in many East London residents' everyday lives and not necessarily related to the use of migrant-run eateries. Within eateries, fleeting social interactions across ethnic and cultural differences are commonplace, but customers and staff rarely engage in in deeper interactions. This is not to deny the possible existence of what Hüttermann (2018) describes as 'intimate market society' where customers and local traders sometimes develop more intimate social relations across differences because of the regularity with which they interact. But there are many other sites in East London where it its more likely that such convivial relations across differences are formed (Wessendorf, 2014). In Nishi-Ogikubo, however, the situation is very different.

\section{West Tokyo: intercultural eating as adaptation to Japanese society}

Tokyo is a global food city with tens of thousands of Chinese, Korean, European and other 'ethnic' eateries. It also may be unique among large global cities in the extent to which 'ethnic' eateries are owned by resident nationals rather than migrants. Low-levels of migration for decades have meant that small-scale Japanese entrepreneurs (often rural-to-urban migrants from other parts of Japan) filled an emerging niche for 'foreign' cuisines in the city. This is most evident in the long-standing Chinese restaurant sector, one of the most common genres of restaurant in urban Japan. Nishi-Ogikubo, like most Tokyo neighbourhoods, has several long-standing 'neighbourhood Chinese' (machi chuka) restaurants run by aging Japanese owners. These are not intercultural meeting spaces in our sense, with Japanese owners serving familiar localized Chinese (chuka ryouri) dishes that most Japanese patrons now regard as nostalgic rather than exotic (Farrer, 2018).

More recently in Nishi-Ogikubo, we see new ethnic restaurants owned by Japanese nationals who have travelled to foreign countries or who learned to prepare these foods in other restaurants in Japan. These include an Uzbek wine bar, a Mexican, Singaporean, and a South Indian restaurant, and there are several pricier French and Italian restaurants run by chefs with professional training in Europe. These are places of everyday culinary diversity for cosmopolitan Tokyoites, but they involve negligible social diversity, since the owners and nearly all customers are Japanese. Nonetheless, the presence of such diverse eateries has facilitated the entry of migrant-owned businesses into the neighbourhood. For example, in one dense commercial district near the main commuter railway station in Nishi-Ogikubo, the success of a Thai cuisine eatery, run by young Japanese, encouraged migrants to set up businesses in the same narrow pedestrian alleyway. The realtor who managed the property also spoke positively of these migrant tenants. There are now Greek, Bangladeshi, Chinese and Korean eateries, all run by migrants from these respective countries, representing a visible concentration of migrant businesses in a neighbourhood where migrants are not ordinarily highly visible. A 
migrant from China also runs the Okinawan restaurant on the alleyway (see Farrer, 2019). Much as in London, these are welcoming spaces for patrons from any backgrounds. The interactions between the largely Japanese customers and migrant proprietors is part of the atmosphere consumed in these spaces. As in the case of some Asian eateries in the USA, migrant proprietors may use their distinctive physical presence and appearance to represent these spaces as both 'exotic' and authentic (Hirose \& Pih, 2011).

Except for a British pub that opened in 2019, no other businesses in Nishi-Ogikubo are 'ethnic eateries' in which it would be common to find a large group of migrants of one ethnicity on a particular evening. Central Tokyo has only a few neighbourhoods with a concentration of migrants great enough to support restaurants catering specifically to the tastes of patrons from their own community (and Japanese are the majority of customers even in most of these). This includes, for example, Chinese restaurants frequented by new Chinese migrants in the 'New Chinatown' of Ikebukuro (see Coates, 2020). In West Tokyo, with its relatively small and dispersed migrant populations, nearly all migrant eateries are oriented towards the dominant Japanese community. This means the owners must adapt to the requirement of the majority, including speaking fluent Japanese. As Kharel (2016) quotes a Nepali restaurant owner in Tokyo:

Here, without speaking Japanese you cannot join a Japanese nomikai (drinking party), and without joining a nomikai you can't make good Japanese friends, and without making good Japanese friends, you can't succeed in business in Japan (Kharel, 2016, p. 189).

As this quote shows, drinking (and socializing over drinks) is an important requirement of the Japanese food service, and many owners, regardless of their own cultural background, see it as a necessity. In Nishi-Ogikubo, Babu, a restaurant owner from Bangladesh, described the necessity of drinking with customers in his small eatery. He also sees drinking as a way of bonding with the customers and creating a community of regulars. The opening hours for his eatery are 6 p.m. to 3 a.m., Babu explained, and the most popular time is the hour after midnight when the bar hoppers drop by for a latenight curry and a beer. Many are curious to try the gin from Bangladesh or wine from India. There are many customers drinking alone, including women. 'People get to know each other and become friends. Some couples have met here and got married,' he said. Regulars, including retirees living in the neighborhood, also chat with Babu, usually about their own recent activities.

As Babu's case shows, community norms of interaction shape sociability in migrantrun spaces. In the small independent izakaya (Japanese taverns) that dominate the area around the commuter train station, customers gather primarily in the evening for food and drinks. Although the migrant-owned eateries on this street offer a taste and imagery of exotic locales, they operate in much the same fashion as the small neighbouring Japanese izakaya. Friendly conversation between the manager and the customers, and usually between customers at the bar, is expected (Molasky, 2014; Taniguchi, 2017), creating a type of 'intercultural third place' in which Japanese customers interact with the migrant staff, though almost entirely in Japanese and according to Japanese cultural norms. This is thus more of a performance of cultural accommodation and 
hospitality on the part of the migrant owner, rather than a shift in behaviour on both sides. Relationships between managers and customers can be quite intimate, however. As one Chinese bar manager explained, she has also organized trips to Taiwan together with her regular customers, a common pattern in the small bars and eateries in the area, including those run by migrants. Her bar is a lively site of joking and flirtations, especially among the younger customers, but also conversations about more serious topics such as international affairs. Regulars include Japanese white-collar employees, foreign English teachers, younger people working in the food and beverage sector and a few students.

The norms of interaction are influenced by the scale and design of urban space, in this case the dominance of micro-scale eateries. As Jacobs suggests, urban spaces on a 'human scale' more easily sustain community (Jacobs, 1961). In Nishi-Ogikubo many eateries are much smaller than anything commonly seen in Western cities. Many are only 13 square meters in floor area and seat a maximum of six patrons in the bar area. Others have extra seating upstairs allowing for up to 20 patrons. The small scale of West Tokyo's migrant eateries means that communication among customers sitting along the bar is expected (Farrer, 2019, 2021).

Because of their size, small izakaya eateries in Tokyo have the feel of a private drinking space catering to regulars, which may be intimidating for migrants from other countries, particularly if they are not confident in their Japanese. Migrants generally feel more welcome, or less pressured, when entering migrant run eateries. In the spaces Farrer observed in Nishi-Ogikubo, this creates a further opportunity for intercultural contacts with Japanese customers, who remain the majority. Because these eateries are mid-priced, the migrant customers tend to be professionals (often teachers) or students, often from developed countries (rarely from the same place as the migrant restaurant owners). Migrant customers may speak Japanese or English (very rarely other languages) with Japanese customers.

For the Japanese regulars in this area, these small ethnic eateries have become a space of intercultural communication that is otherwise relatively rare for Japanese in the neighbourhood. Though it takes place in a fashion that is largely organized around familiar Japanese patterns of sociability (drinking along a bar), intercultural interactions are one attraction of these bars for Japanese hoping to practice English or otherwise interact with foreigners.

Overall, the dominant Japanese social norms and language shape the expectations of how customers interact, even within migrant-owned spaces. A partial exception to this pattern observed in this fieldwork was the new British pub in Nishi-Ogikubo. It is managed by a Japanese proprietor and her British husband, both of whom speak English and Japanese. When several English-speaking customers gather, their conversations are in English. Topics of conversation centre on shared migrant experiences or global concerns (immigrant experiences, international politics, etc). However, when Japanese patrons are the majority, which is often the case, the conversations usually switch to Japanese or a mix of the languages. Because English is a global language, and British pub culture is familiar to Japanese from film and television representations, this commercial eatery is the only one observed in this neighbourhood in which Japanese customers are able and willing to adjust to migrant practices of sociability, if only speaking a few sentences in English to the foreign patrons. 
Beyond the commercial eateries around the station, the relatively low density of migrants in the neighbourhood means that interactions between Japanese residents and migrants are relatively rare for the Japanese (though commonplace and unavoidable for the migrants). There are migrants, such as the Nepali cooks interviewed by Kharel (2016), who socialize almost entirely in networks of other Nepalis, but most migrants living in Nishi-Ogikubo work in the broader Japanese economy and find themselves interacting with the Japanese majority in most everyday situations.

The patterns of intercultural exchanges over food among neighbours mirror those in the commercial eateries in terms of the dominance of Japanese norms of sociability. Most of this happens in contexts created by the Japanese majority. This can include neighbourhood events, such as festivals at schools or temples, or informal gatherings such as 'cherry blossom viewing' parties in the spring. Personal invitations to eat at homes are rare among non-kin in the neighbourhood. Migrants thus have few opportunities to share their own culinary culture with Japanese neighbours, except for a few organized 'international' festivals, such as the large annual one organized in the larger neighbouring community of Kichijoji in West Tokyo. These, however, do not involve immediate neighbours, but rather commercial vendors, and are unlikely to result in sustained social ties. One exception Farrer observed (and actually helped organize) was a neighbourhood Halloween party, involving 'trick-or-treating' and an informal block party among neighbours. Participation by Japanese neighbours has been sustained and enthusiastic, reaching over 200 persons every year for the past decade. This type of sharing of a foreign culture seems to have been possible, because Halloween was an American custom that neighbours were familiar with and therefore could embrace, a pattern also seen in the relatively new British pub. The hegemonic nature of AngloAmerican pop culture and the English language probably plays a role in this exchange. In all these cases, the chance to speak English is an attraction for Japanese, who see foreigners as a rarity, and English as a useful skill.

In summary, the situation in West Tokyo contrasts greatly with that of the superdiverse neighbourhoods in East London. Ethnic food is part of the expected everyday diversity of life in Tokyo as global city. However, the long-term presence of ethnic food in Tokyo does not necessarily entail or require the presence of migrants, since Japanese also run 'ethnic' restaurants. Migrants do have an advantage in this niche, however, since they represent 'authenticity' through their presence (Hirose \& Pih, 2011), and the numbers of migrant-run eateries are increasing. The small number of migrants in Nishi-Ogikubo and neighbouring areas means that the migrant-run eatery is one of the few places in which Japanese residents come into contact with migrants socially. If this is a take-out stand or a restaurant with many tables, the interactions may be momentary, like in London. But in the small and intimate bar-like eateries near the station, regular customers may become very familiar with the migrant managers or owners. These spaces are not just 'cosmopolitan canopies' to use the term of Elijah Anderson, in which people from different backgrounds interact civilly and usually distantly in central city urban spaces (Anderson, 2011), but smaller scale 'intercultural third places' in which people interact on very familiar terms, though only in this limited temporal and spatial context. Ties may be sustained from visit to visit, but rarely go beyond the space-time bubble of 'drinking together'. Beyond these special spaces, the chances for migrants to share their foodways with Japanese residents also are limited, but when 
occasions are created, migrants typically report a positive reception, showing an interest among Japanese in social interactions based upon food, despite (or perhaps because of) their rarity.

\section{Conclusion}

This article has looked at migrant-run eateries in two vastly different contexts in East London and West Tokyo. By drawing on the notions of 'contact zones' (Pratt, 1991) and 'third places' (Oldenburg and Brissett, 1982), it examined the role such eateries play in intercultural relations between the migrant proprietors and their customers (and sometimes between customers). It identified three main factors which shape such interactions: the demographic nature of each urban area, the physical set up of such eateries, and the cultural norms of interaction within eateries in each context.

In the context of East London's commonplace diversity, where interactions with people of different cultural, ethnic, religious and linguistic backgrounds are the norm in public and semi-public spaces, migrant-run eateries do not specifically stand out as intercultural third places, but interactions in such restaurants are simply part of the broader picture of everyday social encounters with people of various backgrounds. In fact, in East London, most public and semi-public spaces could be described as commonplace intercultural third places, and there are few such places where residents do NOT interact with people of different backgrounds. While such interactions are commonplace, this does not mean that people form closer social relations across differences, an issue discussed elsewhere (Wessendorf, 2014).

In the context of West Tokyo, in contrast, migrant-run eateries are important sites of intercultural relations. They represent one of the few places where Japanese residents get in contact with migrants. While this is due to the demographic context of NishiOgikubo, where immigration is relatively new, the kinds of relations formed within such eateries differ from those in East London because of the way in which they are spatially set up. The small scale of eateries and their proximity both to each other and the commuter rail station make them convenient stops for repeat customers who treat them as a space of repeated intimacy. In this situation, both Japanese and migrant regular customers become part of this 'nocturnal public sphere' of alcohol-fuelled communication and conviviality (Molasky, 2014; Taniguchi, 2017). Because of the small spatial scale, conviviality and sociability are expected regardless of the background of customers (Farrer, 2021). Sociability is also fostered because migrant owners (and customers) conform to Japanese norms of nocturnal conviviality, particularly the culture of drinking. If they fail to do so, patrons would go elsewhere. Japanese customers, however, still may regard these as cross-cultural encounters, since they involve novel forms of food and drink as well as interactions with 'foreigners.' Migrant customers also frequent these spaces, though they form a small minority in all but a few places. In such an 'intercultural third place,' the social ties, even among regulars, rarely extend beyond the space and time of 'drinking together.' This is not to downplay the importance of this space for customers, who may come several times a month. This demonstrates that even in neighbourhoods of emerging diversity, which offer only limited spaces for interethnic contact and sociability, these spaces remain sociologically significant. Outside of these commercial spaces, migrants remain very rare in West Tokyo, and there are few 
opportunities for sharing their foods with Japanese neighbours, giving commercial eateries special significance.

To summarise, migrant-run eateries can take vastly different functions depending on the demographic context, the norms of social interaction in such spaces and their physical set up. Thus, the presence of migrant-run eateries as such does not necessarily lead to increased intercultural interactions, but rather, it is what happens within them regarding cultural norms of interaction that plays a decisive role. Scholarship focussing on the role of third places for intercultural relations has rarely taken into account the importance of both the physical set up and the cultural norms of interaction within such places. With the contrasting examples of London and Tokyo, this paper has highlighted how the same kinds of intercultural third places can have very different functions in different contexts.

\section{Acknowledgements}

We would like to thank Jenny Phillimore and Gracia Liu-Farrer for the organisation of the workshop on old and new migration, Tokyo, December 2019. We would also like to thank Nando Sigona, Jenny Phillimore and two anonymous reviewers for comments on earlier versions of the paper.

\section{Authors' contributions}

James Farrer is responsible for the empirical material on Tokyo, and Susanne Wessendorf for the material in London. Conceptual parts of the paper were jointly written. The authors read and approved the final manuscript.

\section{Funding}

The research in London was funded by the Max Planck Institute for the Study of Religious and Ethnic Diversity, and the International Inequalities Institute, London School of Economics. The research in Tokyo was funded by Sophia University Research Institute and the Japan Society for the Promotion of Science (kaken).The workshop where this paper was first presented was funded by the ESRC, grant ref: ES/S013245/1 for the NODE UK/Japan Network; and the Japan Foundation Grant for Intellectual Exchanges and Conferences.

\section{Availability of data and materials}

The datasets generated and/or analyzed during the current study are not publicly available to protect the anonymity of the research participants, but are available from the corresponding author on reasonable request.

\section{Declarations}

\section{Competing interests}

The authors declare that they have no competing interests.

\section{Author details}

${ }^{1}$ Centre for Trust, Peace and Social Relations (CTPSR), Coventry University, Coventry CV1 2TL, UK. ${ }^{2}$ Faculty of Liberal Arts, Sophia University, Kioicho 7-1, Chiyoda-ku, Tokyo 102-8554, Japan.

Received: 24 August 2020 Accepted: 11 March 2021

Published online: 30 June 2021

\section{References}

Amin, A. (2002). Ethnicity and the multicultural city: Living with diversity. Environment and Planning A, 24, 959-980.

Anderson, E. (2011). The cosmopolitan canopy: Race and civility in everyday life. W. W. Norton \& Co.

Assael, B. (2013). Gastro-cosmopolitanism and the restaurant in late Victorian and Edwardian London. The Historical Journal, 56(3), 681-706. https://doi.org/10.1017/S0018246X13000071.

Bhabha, H. K. (1994). The location of culture (vol. xiii, p. 285). Routledge.

Buettner, E. (2008). "Going for an Indian": South Asian restaurants and the limits of multiculturalism in Britain. The Journal of Modern History, 80(4), 865-901. https://doi.org/10.1086/591113.

Butler, T., \& Hamnett, C. (2011). Ethnicity, class and aspiration: Understanding London's new East End. Policy. https://doi.org/1 $0.2307 /$ j.ctt9qganc.

Ceccarini, R. (2011). Pizza and pizza chefs in Japan: A case of culinary globalization. Brill.

Coates, J. (2020). Between product and cuisine: The moral economies of food among young Chinese people in Japan. Journal of Current Chinese Affairs. https://doi.org/10.1177/1868102619898927.

Cook, I. (2008). Geographies of food: Mixing. Progress in Human Geography, 32(6), 821-833. https://doi.org/10.1177/0309132 508090979 .

Cwiertka, K. J. (2006). Modern Japanese cuisine: Food, power and national identity. Reaktion Books.

Farrer, J. (2010). Eating the west and beating the rest: Culinary Occidentalism and urban soft power in Asia's global food cities. In J. Farrer (Ed.), Globalization, food and social identities in the Asia Pacific region (pp. 128-149). Sophia University Institute of Comparative Culture. 
Farrer, J. (2015). Introduction: Travelling cuisines in and out of Asia: Towards a framework for studying culinary globalization. In J. Farrer (Ed.), Globalization and Asian cuisines: Transnational networks and contact zones (pp. 1-20). Palgrave Macmillan.

Farrer, J. (2018). The decline of the neighborhood Chinese restaurant in urban Japan. Jahrbuch für Kulinaristik - The German Journal of Food Studies and Hospitality, 2, 197-222.

Farrer, J. (2019). Grimy heritage: Organic Bar streets in Shanghai and Tokyo. Built Heritage, 3, 73-85.

Farrer, J. (2021). The space-time compression of Tokyo street drinking. Food, Culture and Society, 24(1), 49-65.

Gilroy, P. (2006). Colonial crimes and convivial cultures (Keynote speech presented at the Rethinking Nordic Colonialism exhibition).

Grillo, R. (2018). Interculturalism and the politics of dialogue. B and RG Books of Lewes.

Griswold, W. (2012). Cultures and societies in a changing world. Sage.

Gunew, S. (2000). Introduction: Multicultural translations of food, bodies, language. Journal of Intercultural Studies, 21(3), $227-$ 237. https://doi.org/10.1080/713678979.

Hackney Council (2013). Census 2011. Ethnicity, identity, language and religion in hackney. Hackney Council.

Hackney Council (2019). Hackney facts and figures leaflet. London Borough of Hackney.

Hall, S. (2012). City, street and citizen: The measure of the ordinary. Routledge. https://doi.org/10.4324/9780203118597.

Hall, S., King, J., \& Finlay, R. (2017). Migrant infrastructure: Transaction economies in Birmingham and Leicester. Urban Studies, 54(6), 1311-1327. https://doi.org/10.1177/0042098016634586.

Hashimoto, K. (2015). Izakaya no Sengoshi [Postwar History of Izakaya]. Shodensha.

Heap, C. (2008). Slumming: Sexual and racial encounters in American nightlife, 1885-1940. University of Chicago Press.

Heldke, L. (2015). Exotic appetites: Ruminations of a food adventurer. Routledge. https://doi.org/10.4324/9781315822068.

Hirose, A., \& Pih, K. K.H. (2011). 'No Asians working here': Racialized otherness and authenticity in gastronomical orientalism. Ethnic and Racial Studies, 45, 1482-1501.

HM Government (2018). Integrated Communities Strategy green paper.

Hooks, B. (1998). Eating the other: Desire and resistance. In R. Scapp, \& B. Seitz (Eds.), Eating culture (pp. 181-200). State University of New York Press.

Hüttermann, J. (2018). Fiqurationsprozesse der Einwanderungsgesellschaft. Zum Wandel der Beziehungen zwischen Alteingesessenen und Migranten in deutschen Städten. Transcript. https://doi.org/10.14361/9783839437445.

Iwabuchi, K. (2002). Recentering globalization: Popular culture and Japanese transnationalism. Duke University Press. https://doi. org/10.1215/9780822384083.

Jacobs, J. (1961). The death and life of great American cities (p. 458). Cape.

Jones, T., Ram, M., Li, Y., Edwards, P., \& Villares, M. (2015). Super-diverse Britain and new migrant enterprises (IRiS working paper series, no. 8). Institute for Research into Superdiversity.

Kharel, D. (2016). From Lahures to global cooks: Network migration from the Western Hills of Nepal to Japan. Social Science Japan Journal, 19(2), 173-192. https://doi.org/10.1093/ssjj/jyw033.

Laurier, E., \& Philo, C. (2006). Cold shoulders and napkins handed: Gestures of responsibility. Transactions of the Institute of British Geographers, 31(2), 193-207. https://doi.org/10.1111/j.1475-5661.2006.00205.x.

Light, I. (1974). From vice district to tourist attraction: The moral career of American Chinatowns, 1880-1940. Pacific Historical Review, 43(3), 367-394. https://doi.org/10.2307/3638262.

Lofland, L. H. (1998). The public realm: Exploring the city's quintessential social territory. Aldine de Gruyter.

London Borough of Newham (2011). Newham key statistics based on mayhew data. London Borough of Newham.

London Borough of Newham (2016). Understanding Newham 2015. In Findings from wave 8 of the Newham household panel surveys. Ipsos MORI Social Research Institute.

Molasky, M. (2014). Nihon no Izakaya Bunka: Akachochin no Miryoku wo Saguru [Japan's Izakaya Culture: Exploring fascination of red lantern]. Kobunsha Shinsho.

Narayan, U. (1995). Eating cultures: Incorporation, identity and Indian food. Social Identities, 1(1), 63-86. https://doi.org/10.1 080/13504630.1995.9959426.

Nava, M. (2007). Visceral cosmopolitanism: Gender, culture and the normalisation of difference. Berg. https://doi.org/10.5040/ 9781350048973

Neal, S., Bennett, K., Cochrane, A., \& Mohan, G. (2018). Lived experiences of multiculture: The new social and spatial relations of diversity. Routledge.

Nowicka, M., \& Vertovec, S. (2014). Comparing convivialities: Dreams and realities of living-with-difference. European Journal of Cultural Studies, 17(4), 341-356. https://doi.org/10.1177/1367549413510414.

Oldenburg, R., \& Brissett, D. (1982). The third place. Qualitative Sociology, 5(4), 265-284. https://doi.org/10.1007/BF00986754.

Panayi, P. (2008). Spicing up Britain: The multicultural history of British food. Reaktion.

Pécoud, A. (2004). Entrepreneurship and identity: Cosmopolitanism and cultural competencies among German-Turkish businesspeople in Berlin. Journal of Ethnic and Migration Studies, 30(1), 3-20. https://doi.org/10.1080/13691830320001 70141.

Pratt, M. (1991). Arts of the Contact Zone. Profession, 33-40. http:/www.jstor.org/stable/25595469. Accessed 23 Apr 2021.

Ray, K. (2016). The ethnic restaurateur. Bloomsbury Publishing. https://doi.org/10.5040/9781474269414.

Rhys-Taylor, A. (2017). Food and multiculture: A sensory ethnography of East London. Bloomsbury Academic.

Sandercock, L. (2003). Cosmopolis II: Mongrel cities of the 21st century. Continuum.

Sewell W. H. (2005). The concept(s) of culture. In G. M. Spiegel (Ed.), Practicing history: New directions in historical writing after the linguistic turn (pp. 76-95). Psychology Press.

Solt, G. (2014). The untold history of ramen: How political crisis in Japan spawned a global food craze. University of California Press. https://doi.org/10.1525/california/9780520277564.001.0001.

Suginami City. (2019). Suginami city open data. https://www.city.suginami.tokyo.jp/opendata/index.html.

Suttles, G. D. (1968). The social order of the slum: Ethnicity and territory in the inner city. University of Chicago Press.

Swidler, A. (1986). Culture in action: Symbols and strategies. American Sociological Review, 51(2), 273-286. https://doi.org/10.23 07/2095521.

Taniguchi, K. (2017). Nihon no yoru no kökyō-ken: Sunakku kenkyū josetsu [Japan's nighttime public sphere: An introduction to snack research]. Shiromizusha. 
Turgeon, L., \& Pastinelli, M. C. (2002). "Eat the world": Postcolonial encounters in Quebec city's ethnic restaurants. The Journal of American Folklore, 115, 247-268.

Valentine, G. (2008). Living with difference: Reflections on geographies of encounter. Progress in Human Geography, 32(3), 323-337. https://doi.org/10.1177/0309133308089372

Vaughan, L. (2015). The ethnic marketplace as point of transition. In A. J. Kershen (Ed.), London the promised land revisited (pp. 35-54). Ashgate.

Vertovec, S. (Ed.) (2015). Diversities old and new. Migration and socio-spatial patterns in New York, Singapore and Johannesburg. Palgrave Macmillan.

Vertovec, S., \& Wessendorf, S. (Eds.). (2010). The Multiculturalism Backlash. European Discourses, Policies and Practices. London: Routledge.

Warde, A. (2000). Eating globally: Cultural flows and the spread of ethnic restaurants. In D. Kalb, M. van der Land, R. Staring, B. van Steenbergen, \& N. Wilterdink (Eds.), The ends of globalization: Bringing society back in (pp. 299-316). Rowman \& Littlefield.

Watson, S. (2009). Brief encounters of an unpredictable kind: Everyday multiculturalism in two London street markets. In A. Wise, \& S. Velayutham (Eds.), Everyday multiculturalism (pp. 125-139). Palgrave Macmillan.

We Made That, \& LSE Cities (2017). High streets for all. Mayor of London.

Wessendorf, S. (2014). Commonplace diversity. Social relations in a super-diverse context. Palgrave Macmillan. https://doi.org/1 $0.1057 / 9781137033314$.

White, M. (2012). Coffee life in Japan. University of California Press.

Williams, R. (1995). The sociology of culture. University of Chicago Press.

Wise, A. (2011). Moving food: Gustatory commensality and disjuncture in everyday multiculturalism. New Formation, 74(74), 82-107. https://doi.org/10.3898/NewF.74.05.2011.

Wood, P., \& Landry, C. (2007). The intercultural city: Planning for diversity advantage. Earthscan.

Zelinsky, W. (1985). The roving palate: North America's ethnic restaurant cuisines. Geoforum, 16(1), 51-72.

\section{Publisher's Note}

Springer Nature remains neutral with regard to jurisdictional claims in published maps and institutional affiliations.

\section{Submit your manuscript to a SpringerOpen ${ }^{\circ}$ journal and benefit from}

- Convenient online submission

- Rigorous peer review

- Open access: articles freely available online

- High visibility within the field

Retaining the copyright to your article

Submit your next manuscript at $>$ springeropen.com 